\title{
ANALISIS PENDAPATAN DAN BIAYA POKOK USAHATANI KEDELAI DI KECAMATAN AMBARAWA KABUPATEN PRINGSEWU
}

(Analysis of Revenue and Standard Cost of Soybean Farming in Ambarawa Subdistrict Pringsewu Regency)

Putri Alamanda, Agus Hudoyo dan Achdiansyah Soelaiman

Jurusan Agribisnis, Fakultas Pertanian, Universitas Lampung, Jl. Prof. Dr. Soemantri Brojonegoro No. 1

Bandar Lampung 35145, e-mail: agus.hudoyo@fp.unila.ac.id

\begin{abstract}
The objectives of this research were to analyze the revenue and the standard cost of the soybean farming in Ambarawa District, Pringsewu Regency. Respondents were the soybean farmers chosen by using simple random sampling method. The data were the soybean farming in the Dry Season (DS) 2017. The data were analyzed by using the financial analysis. Based on the reseach, the average soybean productivity was 1.31 ton/ha. The average net revenue over the cash costs and over the total cost respectively were IDR 6.76 million/ha and IDR 1.45 million/ha. The average standard cost for producing soybean was IDR 7,061/kg and its $95 \%$ confidence interval was IDR 5,559/kg - IDR 8,562/kg.
\end{abstract}

Key words: revenue, soybean, standard cost.

\section{PENDAHULUAN}

Kedelai yang diolah menjadi lauk dalam bentuk tahu dan tempe merupakan salah satu komoditas pangan utama penduduk Indonesia. Di Indonesia, lebih dari 80 persen kedelai digunakan untuk konsumsi bahan makanan, seperti tahu, tempe, dan kecap; 10 persen untuk industri non-makanan; 2 persen untuk benih/bibit; 5 persen tercecer dan sisanya untuk pakan. Kebutuhan akan kedelai tersebut terus meningkat setiap tahun. Kebutuhan kedelai secara berturut-turut pada 2015 dan 2016 sebesar 2,42 juta ton dan 2,53 juta ton (Kementerian Pertanian 2016).

Produksi kedelai di Indonesia secara berturut-turut pada 2015 dan 2016 yaitu sebesar 963,02 ribu ton dan 859,65 ribu ton. Data ini menunjukkan bahwa pada 2016 produksi kedelai di Indonesia hanya mampu memenuhi 32,24 persen dari total kebutuhan kedelai (Kementerian Pertanian 2016). Produksi kedelai yang belum mencukupi kebutuhan kedelai menunjukkan bahwa Indonesia belum berswasembada kedelai. Oleh sebab itu, Indonesia harus mengimpor kedelai untuk memenuhi kebutuhannya.

Pemenuhan kebutuhan pasokan kedelai yang masih tergantung pada impor menunjukkan bahwa upaya swasembada kedelai yang dilakukan pemerintah belum tercapai. Kebutuhan impor yang tinggi menyebabkan minat petani dalam berusahatani kedelai menurun. Hal itu disebabkan karena kedelai impor secara harga dan kualitas lebih baik dari kedelai lokal (Sudaryanto dan Swastika 2016). Oleh sebab itu, upaya peningkatan produksi kedelai lokal melalui intensifikasi perlu dilakukan agar swasembada kedelai tercapai. Petani akan meningkatkan produksi apabila usahatani kedelai yang dijalankan menguntungkan, sehingga untuk mengetahui seberapa besar keuntungan usahatani kedelai perlu dilakukan penelitian mengenai analisis pendapatan.

Tingkat pendapatan usahatani dipengaruhi oleh harga jual, sehingga pemerintah membuat kebijakan harga acuan untuk melindungi petani. Harga acuan pemerintah untuk kedelai di tingkat petani diatur dalam Peraturan Menteri Perdagangan Republik Indonesia Nomor 58 Tahun 2018. Berdasarkan peraturan ini, harga kedelai di tingkat petani sebesar Rp 8.500/kg. Harga acuan ini seharusnya lebih besar dari biaya pokok. Terkait hal ini, maka perlu dilakukan penelitian mengenai biaya pokok usahatani kedelai.

Penelitian mengenai analisis pendapatan usahatani kedelai sudah dilakukan oleh peneliti-peneliti terdahulu, seperti Barokah (2011), Farikin et al. (2016), Messiana et al. (2014) dan Windi et al. (2017). Penelitian mengenai biaya pokok kedelai pernah diteliti sebelumnya oleh Subagja et al. (2017), namun penelitian yang menganalisis pendapatan dan biaya pokok usahatani kedelai di Kabupaten Pringsewu belum pernah dilakukan. Oleh karena itu, penelitian ini bertujuan untuk mengetahui pendapatan dan biaya pokok usahatani 
kedelai di Kecamatan Ambarawa Kabupaten Pringsewu.

\section{METODE PENELITIAN}

Penelitian ini dilakukan di Kecamatan Ambarawa, Kabupaten Pringsewu. Penentuan lokasi dilakukan secara sengaja dengan pertimbangan bahwa Kecamatan Ambarawa memiliki produksi kedelai tertinggi dibandingkan dengan kecamatankecamatan lainnya di Kabupaten Pringsewu. Produksi kedelai Kecamatan Ambarawa yaitu sebesar 128 ton (Dinas Pertanian Kabupaten Pringsewu 2017)

Responden dalam penelitian ini adalah petani kedelai yang berada di Pekon Ambarawa Barat, Pekon Sumber Agung dan Pekon Margodadi. Jumlah batas minimal yang harus diambil oleh peneliti yaitu sebanyak 30 responden dengan asumsi sudah menyebar secara merata atau sudah mewakili jumlah populasi yang ada, sehingga responden yang diambil yaitu sebanyak 60 orang yang dipilih dengan menggunakan metode acak sederhana (Cohen 2007). Pengumpulan data dilaksanakan pada bulan Desember 2017-Februari 2018. Jenis data yang dikumpulkan dalam penelitian ini adalah data primer dan sekunder. Data ini diperoleh dengan mewawancarai langsung petani dengan menggunakan kuisioner. Metode analisis yang digunakan dalam penelitian ini yaitu analisis usahatani.

Pendapatan usahatani adalah selisih penerimaan dengan semua biaya usahatani. Biaya usahatani kedelai yang dimaksudkan dalam penelitian ini terdiri dari dua jenis biaya yaitu biaya tunai dan biaya diperhitungkan. Biaya tunai terdiri dari biaya sarana produksi yang bersumber dari pembelian, tenaga kerja luar keluarga, iuran air dan pajak. Biaya diperhitungkan terdiri dari biaya sarana produksi yang bukan dari pembelian, tenaga kerja dalam keluarga, penyusutan, sewa lahan, dan bunga modal. Berikut merupakan rumus pendapatan usahatani dalam penelitian ini:

1. Pendapatan atas biaya tunai $=$ Penerimaan biaya tunai

2. Pendapatan atas biaya total $=$ Penerimaan biaya total

Keterangan:

Penerimaan

Biaya tunai = Biaya yang dikeluarkan dalam bentuk uang

Biaya total = Biaya tunai + diperhitungkan
Tujuan kedua dianalisis dengan menggunakan analisis biaya pokok. Biaya pokok merupakan pembagian antara biaya total dengan jumlah output yang dihasilkan. Secara matematis, perhitungan biaya pokok didapatkan dengan menggunakan rumus sebagai berikut.

$\mathrm{BP}=\frac{\mathrm{TC}}{\mathrm{Y}}$

Keterangan:

$\mathrm{BP}=$ Biaya pokok

$\mathrm{TC}=$ Biaya total

$\mathrm{Y}=$ Produksi

Setelah diperoleh biaya pokok kemudian dihitung rata-rata biaya pokok dengan rumus berikut:

$\overline{\mathrm{BP}}=\frac{\sum_{\mathrm{i}=1 \mathrm{BP}_{\mathrm{i}}}^{\mathrm{n}}}{\mathrm{n}}$

Keterangan:

$\overline{\mathrm{BP}}=$ Rata-rata biaya pokok

$\mathrm{BP}_{\mathrm{i}}=$ Biaya pokok responden ke- $\mathrm{i}$

$\mathrm{n} \quad=$ Jumlah sampel (60)

Rata-rata biaya pokok yang telah didapat kemudian dilakukan perhitungan selang kepercayaannya dengan menggunakan tingkat kepercayaan sebesar 95 persen $(\alpha=5 \%)$. Perhitungan selang kepercayaan biaya pokok dapat dilihat sebagai berikut (Walpole 1995):

$\overline{\mathrm{BP}}-\mathrm{t}_{\alpha / 2} \frac{\mathrm{s}}{\sqrt{\mathrm{n}}}<\overline{\mathrm{BP}}<\overline{\mathrm{BP}}+\mathrm{t}_{\alpha / 2} \frac{\mathrm{s}}{\sqrt{\mathrm{n}}}$

Keterangan:

$\overline{\mathrm{BP}} \quad=$ Rata-rata biaya pokok

$\mathrm{s} \quad=$ Simpangan baku

$\alpha=$ Taraf nyata $(5 \%)$

$\mathrm{n} \quad=$ Jumlah sampel (60)

\section{HASIL DAN PEMBAHASAN}

Tingkat umur responden pada penelitian ini sangat bervariasi, dimulai dari umur 30 tahun sampai 68 tahun dengan rata-rata umur 49 tahun. Tingkat pendidikan yang paling banyak dicapai oleh responden adalah tamatan Sekolah Dasar (SD) sebanyak 28 orang dengan persentase sebesar 46,67 persen. Sebanyak 41 kepala rumah tangga memiliki tanggungan sebanyak dua sampai lima orang anggota keluarga. Luas lahan usahatani kedelai sangat bervariasi dimulai dari 0,20 ha sampai 1,51 ha dengan luas rata-rata responden sebesar 0,45 ha sebanyak 38 petani. 
Tabel 1. Rata-rata input, tenaga kerja, output, biaya dan pendapatan usahatani kedelai per hektar MK 2017

\begin{tabular}{|c|c|c|c|c|}
\hline Uraian & Satuan & Fisik & Harga/satuan & Nilai \\
\hline Produksi & $\mathrm{Kg}$ & $1.310,00$ & & \\
\hline Penerimaan & $\mathrm{Rp} / \mathrm{kg}$ & & 8.265 & \\
\hline Penerimaan produksi & $\mathbf{R p}$ & & & 10.825 .773 \\
\hline \multicolumn{5}{|l|}{ Biaya produksi } \\
\hline \multicolumn{5}{|l|}{ a. Biaya tunai } \\
\hline Benih & $\mathrm{Kg}$ & 15,28 & 14.000 & 213.967 \\
\hline Pupuk N & $\mathrm{Kg}$ & 45,48 & 2.000 & 90.967 \\
\hline Pupuk P & $\mathrm{Kg}$ & 29,74 & 2.500 & 74.361 \\
\hline Pupuk majemuk & $\mathrm{Kg}$ & 181,40 & 2.600 & 471.640 \\
\hline Insektisida & $\mathrm{L}$ & 1,38 & 220.000 & 304.140 \\
\hline Fungisida & $\mathrm{L}$ & 0,06 & 616.000 & 34.085 \\
\hline Herbisida & $\mathrm{L}$ & 2,68 & 80.000 & 214.244 \\
\hline TKLK & $\mathrm{HOK}$ & 29,00 & 50.000 & 1.450 .083 \\
\hline Mesin & & & & 1.200 .000 \\
\hline Pajak & & & & 16.333 \\
\hline Total biaya tunai & $\mathbf{R p}$ & & & 4.069.821 \\
\hline \multicolumn{5}{|l|}{ b. Biaya diperhitungkan } \\
\hline Benih (milik sendiri) & $\mathrm{Kg}$ & 11,44 & 14.000 & 160.191 \\
\hline Pupuk kandang & $\mathrm{Kg}$ & & 500 & \\
\hline TKDK & $\mathrm{HOK}$ & 24,97 & 50.000 & 1.248 .299 \\
\hline Penyusutan alat & & & & 120.470 \\
\hline Sewa lahan & & & & 3.333 .333 \\
\hline Bunga modal & & & & 243.939 \\
\hline Total biaya diperhitungkan & $\mathbf{R p}$ & & & 5.305 .788 \\
\hline Total biaya & $\mathrm{Rp}$ & & & 9.375 .609 \\
\hline \multicolumn{5}{|l|}{ Pendapatan: } \\
\hline Pendapatan atas biaya tunai & $\mathrm{Rp}$ & & & 6.755 .951 \\
\hline Pendapatan atas biaya total & $\mathrm{Rp}$ & & & 1.450 .164 \\
\hline
\end{tabular}

\section{Penggunaan Benih dan Sarana Produksi}

Selain penggunaan benih, terdapat sarana produksi berupa pupuk, pestisida dan peralatan-peralatan lainnya. Rata-rata input, output, biaya dan pendapatan usahatani kedelai di Kecamatan Ambarawa Kabupaten Pringsewu disajikan pada Tabel 1.

Benih diperoleh petani dengan mengambil dari sisa hasil panen yang lalu dan juga membeli di pasar atau toko pertanian. Varietas kedelai yang ditanam adalah kedelai varietas Gepak Kuning, karena benih jenis ini menurut petani produktivitas dan harga jualnya tinggi. Penggunaan benih kedelai yaitu sebesar 26,73 $\mathrm{kg} / \mathrm{ha}$ dengan harga $\mathrm{Rp}$ $14.000 / \mathrm{kg}$.

Pupuk yang digunakan dalam usahatani kedelai yaitu pupuk $\mathrm{N}$, pupuk $\mathrm{P}$, pupuk majemuk dan pupuk kandang. Menurut BPTP Lampung (2016) untuk lahan sawah kurang subur, rekomendasi takaran pupuk $\mathrm{N}$ yaitu sebesar $50-150 \mathrm{~kg} / \mathrm{ha}$.
Penggunaan pupuk $\mathrm{N}$ untuk lahan subur yaitu sebesar 25-100 kg/ha. Pupuk N yang digunakan dalam usahatani kedelai ini adalah 45,48 kg. Sementara anjuran untuk penggunaan pupuk $\mathrm{P}$ untuk lahan kurang subur yaitu $75-150 \mathrm{~kg} / \mathrm{ha}$ dan penggunaan pupuk $\mathrm{P}$ untuk lahan subur yaitu sebesar $50-100 \mathrm{~kg} / \mathrm{ha}$. Pupuk P yang digunakan per hektar dari rata-rata semua responden termasuk rendah yaitu sebesar $29,74 \mathrm{~kg}$, karena hanya sebagian kecil responden yang menggunakan pupuk P. Apabila menggunakan pupuk majemuk, maka takaran untuk lahan yang kesuburannya rendah adalah 250-300 kg pupuk majemuk/ha, sedangkan untuk lahan yang kesuburannya sedang adalah 150-250 kg pupuk majemuk/ha Penggunaan pupuk majemuk per hektar yang digunakan dalam penelitian ini yaitu $181,40 \mathrm{~kg}$ (BPTP Lampung 2016).

Hama yang ada pada tanaman kedelai di daerah penelitian secara umum adalah kutu kebul, ulat grayak dan penggerek polong. Jenis penyakit pada tanaman kedelai berupa bercak-bercak pada daun. 
Terdapat tiga macam obat-obatan yang digunakan dalam usahatani kedelai yaitu fungisida, herbisida dan insektisida. Fungisida yang digunakan yaitu Score. Herbisida yang digunakan yaitu Bionasa dan Roundup. Insektisida yang digunakan yaitu Starban, Santrino, Virtako dan Regent. Biaya pestisida merupakan biaya terkecil di antara biaya sarana produksi yang digunakan dalam usahatani kedelai. Biaya pestisida terkecil yang dikeluarkan petani adalah biaya fungisida.

Biaya tenaga kerja meliputi biaya pengolahan tanah, penanaman, pemupukan, penyiangan, pengendalian hama, pemanenan, penjemuran, perontokan, penyortiran dan biaya mesin. Biaya tenaga kerja adalah biaya terbesar karena banyak aktivitas yang dilakukan mulai dari pengolahan tanah sampai pasca panen. Usahatani kedelai di daerah penelitian menggunakan tenaga kerja sebanyak 53,96 HOK/ha/MT. Upah per HOK yaitu sebesar Rp 50.000/orang. Kegiatan perontokan biji kedelai dilakukan dengan bantuan tenaga kerja mesin, yaitu power trasher. Mesin power trasher disediakan oleh kelompok tani di suatu tempat tertentu dan dapat digunakan secara bergilir oleh anggotanya. Petani membayar upah mesin dengan sistem borongan dengan harga Rp 1.200.000/ha.

\section{Produksi, Penerimaan dan Pendapatan}

Rata-rata produksi kedelai di Kecamatan Ambarawa Kabupaten Pringsewu berdasarkan hasil penelitian yaitu sebesar 1,31 ton/ha. Ratarata penerimaan usahatani kedelai pada September sampai November 2017 di Kecamatan Ambarawa yaitu sebesar Rp 10.825.773/ha/MT. Penelitian Barokah (2011) di Kabupaten Sukoharjo menunjukkan hasil produksi kedelai per hektar yang sedikit lebih tinggi yaitu sebesar 1,78 ton/ha, namun penerimaannya tidak jauh berbeda dari hasil penelitian ini yaitu sebesar Rp 10.509.794/ha/MT. Hasil penelitian lain yaitu Naftaliasari et al (2015) di Raman Utara juga menunjukkan hasil penerimaan yang tidak jauh berbeda sebesar Rp 12.202.930/ha/MT.

Biaya usahatani kedelai yang dimaksudkan dalam penelitian ini yaitu biaya total yang terdiri dari dua jenis biaya yaitu biaya tunai dan biaya diperhitungkan (Soekartawi 2002). Biaya total yang dikeluarkan dalam penelitian ini lebih rendah dari penerimaan yang didapatkan. Selaras dengan penelitian Windi et al (2017) di Kecamatan Berbak Kabupaten Tanjung Jabung Timur, rata-rata penerimaan usahatani kedelai lebih tinggi dari ratarata biaya yang dikeluarkan. Hal ini berarti bahwa petani di Kecamatan Ambarawa masih mampu untuk menutupi biaya tunai dan biaya diperhitungkan, sehingga masih dapat memperoleh keuntungan dari pendapatan.

Pendapatan atas biaya tunai dan pendapatan atas biaya total yang diperoleh petani secara berturutturut yaitu sebesar $\mathrm{Rp}$ 6.755.951/ha/MT dan $\mathrm{Rp}$ 1.450.164/ha/MT. Hasil penelitian menunjukkan bahwa perhitungan biaya tunai yang didapatkan, tidak jauh berbeda dari penelitian Messiana et al (2014) di SL-PTT Kabupaten Lampung Selatan, pendapatan atas biaya tunai per ha petani kedelai yaitu sebesar Rp 6.319.193/ha/MT.

\section{Biaya Pokok}

Biaya pokok yaitu biaya total yang dikeluarkan per output yang dihasilkan. Perhitungan selang kepercayaan biaya pokok sangat penting, karena mewakili pengeluaran biaya pokok dari masingmasing petani. Rata-rata biaya pokok dan selang kepercayaannya dalam usahatani kedelai disajikan pada Tabel 2.

Berdasarkan perhitungan yang telah dilakukan, biaya pokok yang dikeluarkan petani di lokasi penelitian yaitu sebesar Rp 7.061/kg. Selang kepercayaan rata-rata biaya pokok dengan taraf kepercayaan 95 persen yaitu antara $\mathrm{Rp}$ 5.559$8.562 / \mathrm{kg}$ kedelai.

Tabel 2. Rata-rata biaya pokok dan selang kepercayaan biaya pokok

\begin{tabular}{llr}
\hline Uraian & Satuan & \multicolumn{1}{c}{ Nilai } \\
\hline Produksi & $\mathrm{Kg}$ & $1.309,83$ \\
Biaya total & $\mathrm{Rp}$ & \\
$\quad$ Benih & $\mathrm{Rp}$ & 374.158 \\
$\quad$ Pupuk & $\mathrm{Rp}$ & 836.524 \\
$\quad$ Pestisida & $\mathrm{Rp}$ & 552.469 \\
$\quad$ Tenaga kerja & $\mathrm{Rp}$ & 3.898 .383 \\
$\quad$ Penyusutan & $\mathrm{Rp}$ & 120.470 \\
$\quad$ Pajak & $\mathrm{Rp}$ & 16.333 \\
$\quad$ Sewa lahan & & 3.333 .333 \\
$\quad$ Bunga modal & $\mathrm{Rp}$ & 243.939 \\
Total & $\mathrm{Rp}$ & 9.375 .609 \\
Biaya pokok & & \\
$\quad$ SK 95\% & $\mathrm{Rp} / \mathrm{kg}$ & 7.061 \\
$\quad$ Batas atas & $\mathrm{Rp} / \mathrm{kg}$ & 8.562 \\
$\quad$ Batas bawah & $\mathrm{Rp} / \mathrm{kg}$ & 5.559 \\
Harga acuan pemerintah & $\mathrm{Rp} / \mathrm{kg}$ & 8.500 \\
\hline
\end{tabular}

Berdasarkan hal tersebut, penetapan harga output kedelai seharusnya di atas biaya pokok tertinggi 
(batas atas), sehingga petani kedelai memperoleh keuntungan.

\section{KESIMPULAN}

Rata-rata produktivitas kedelai yaitu 1,31 ton/ha. Rata-rata pendapatan atas biaya tunai usahatani kedelai yaitu Rp 6,76 juta/ha dan pendapatan atas biaya total usahatani kedelai yaitu Rp 1,45 juta/ha. Rata-rata biaya pokok usahatani kedelai yaitu sebesar Rp 7.061/kg kedelai. Hasil tersebut menunjukkan bahwa petani kedelai mengalami keuntungan, karena harga yang diterima oleh petani kedelai lebih besar dari biaya pokok yang dikeluarkan. Selang kepercayaannya pada taraf kepercayaan 95 persen yaitu Rp $5.559-8.562 / \mathrm{kg}$ kedelai.

\section{DAFTAR PUSTAKA}

Barokah U. 2011. Analisis biaya dan pendapatan usahatani kedelai di Kabupaten Sukoharjo SEPA, 8 (1) : 9-13. http://agribisnis.fp. uns.ac.id/wp-content/uploads/2013/10/02Analisis-Biaya-Dan-PendapatanUsahataniKedelai-Di-Kabupaten-Sukoharjo.pdf. September 2018].

BPTP Lampung. 2016. Pemupukan Kedelai Lahan Sawah di Provinsi Lampung. Litbang.pertanian.go.id. Diakses 8 Juli 2018.

Cohen L. 2007. Reasearch Methods in Education (Sixth Editon). Routledge. New York.

Dinas Pertanian Kabupaten Pringsewu. 2017. Data Produksi Kedelai di Kecamatan Ambarawa (Tidak dipublikasikan). Dinas Pertanian Kabupaten Pringsewu. Lampung.

Farikin M, Saparto dan Suharyanto E. 2016. Analisis usahatani kedelai varietas grobogan di Desa Pandanharum Kabupaten Grobogan. Jurnal Agromedia, 34 (1) : 56-63. https://jurnalkampus. stipfarming.ac.id/index.php/am/article/downlo ad/130/128. [5 September 2018].

Kementrian Pertanian. 2016. Buletin Konsumsi Pangan. Pusat Data dan Sistem Informasi Pertanian. Jakarta.

Mesianna MA, Prasmatiwi FE dan Nugraha A. 2014. Analisis efisiensi produksi frontier dan pendapatan usahatani kedelai Sekolah Lapangan Pengelolaan Tanaman Terpadu (SL-PTT) di Kabupaten Lampung Selatan JIIA, 2 (4) : 348-355. http://jurnal.fp. unila.ac.id/index.php/JIA/article/download/98 9/895. [5 September 2018].

Naftaliasari T, Abidin Z dan Kalsum U. 2015. Analisis risiko usahatani kedelai di Kecamatan Raman Utara Kabupaten Lampung Timur. JIIA, 3 (2):148-156. http://jurnal.fp.unila.ac.id/index.php/JIA/articl e/download/1033/938. [5 September 2018].

Soekartawi. 2002. Analisis Usahatani. Raja Grafindo. Jakarta.

Subagja R, Rochdiani D dan Yusuf MN. 2017. Penetapan harga pokok penjualan pada usahatani kedelai (Glycine Max L.) (Suatu kasus di Desa Bantarkalong Kecamatan Cipatujah Kabupaten Tasikmalaya. Jurnal Ilmiah Mahasiswa Agroinfo Galuh, 4 (3) : 402-407. https://jurnal.unigal.ac.id/index. php/agroinfogaluh/article/downloadSuppFile/ 815/260. [5 September 2018].

Sudaryanto T dan Swastika DKS. 2016. Ekonomi Kedelai di Indonesia. Pusat Analisis SosialEkonomi dan Kebijakan Pertanian. Bogor.

Walpole RE. 1995. Pengantar Statistika Edisi ke3. PT Gramedia Pustaka Utama. Jakarta.

Windi MT, Edison, A Saputra. 2017. Analisis pendapatan usahatani kedelai di Kabupaten Jabung Timur Kecamatan Berbak Kabupaten Jabung Timur. Jurnal Pertanian, (53):1-13. https://repository. unja.ac.id/856/. 